\title{
Sintered Eutectoid P/M Steel Behaviour During Cold Upsetting
}

\author{
A. Rajesh Kannan ${ }^{a} *$, K.S. Pandey ${ }^{\mathrm{b}}$, S. Shanmugam ${ }^{\mathrm{c}}, \boldsymbol{R}$. Narayanasamy ${ }^{\mathrm{d}}$ \\ aDepartment of Mechanical Engineering, Thiagarajar College of Engineering, \\ Thiruparankundram, Madurai, 625015 TamilNadu, India \\ ${ }^{\mathrm{b}}$ Maulana Azad National Institute of Technology, \\ Bhopal, 462007 Madhya Pradesh, India \\ ${ }^{\mathrm{C}}$ Department of Mechanical Engineering, National Institute of Technology, \\ Tiruchirappalli, 620015 TamilNadu, India \\ ${ }^{\mathrm{d}}$ Department of Production Engineering, National Institute of Technology, \\ Tiruchirappalli, 620015 TamilNadu, India
}

Received: November 20, 2006; Revised: March 3, 2008

\begin{abstract}
Cold upsetting experiments were carried out on sintered $\mathrm{Fe}-0.8 \% \mathrm{C}$ steel preforms in order to evaluate the technical relationship that exist between the applied stresses against continuous deformation and densification. Powder preforms of $86 \%$ theoretical density and 0.40 of initial aspect ratio were subjected to incremental compressive loading of $0.04 \mathrm{MN}$ under three different friction conditions such as dry, graphite and zinc stearate employed during deformation until fracture appears at free surfaces. Experimental results revealed that the response of applied stresses with induced strain and attained densification exhibits a continuous enhancement but with three different stages. Irrespective of friction conditions the first and third stage shows steep rise, which offers high resistance to deformation, whereas the second stage shows virtually steady state; deformation needed gradual increase in applied stresses but with high rate of densification. Further, preform deformed under without lubricant exhibited maximum strain hardening as well as an enhanced rate of strain hardening through out the deformation in comparison with lubricants employed conditions.
\end{abstract}

Keywords: friction conditions, applied stresses, deformation and densification, strain hardening

\section{Introduction}

Powder metallurgy $(\mathrm{P} / \mathrm{M})$ technology provides total cost savings, unique properties, reliability, special materials, quality and increased performance. In addition, a special feature that $\mathrm{P} / \mathrm{M}$ route possess is the tailor made design and thus a complex shape and tight tolerance can be techno - economically produced ${ }^{1}$. Another key advantage of the $\mathrm{P} / \mathrm{M}$ process is the ability to produce net shape or near net shape high precision components with a very high material yield compared with other traditional metal working process such as stamping, casting, forging and machining. However, a major goal of conventional $\mathrm{P} / \mathrm{M}$ industry is to increase the density to match the properties of wrought materials, since the parts produced through conventional powder metallurgy process involves powder blending, compaction and sintering possess low density. Meaning thereby, presence of sufficiently large amount of pores act as a site of stress risers and stress concentrators resulting in crack initiation and propagation when it is subjected to mechanical application and hence these parts cannot be employed in structural and heavy duty applications. Thus, to enhance the density of porous materials, it is necessary to eliminate or close the pores by the application of one or more deformation process on a conventional $\mathrm{P} / \mathrm{M}$ product. To produce full density or net shape product, many secondary operations were evolved ${ }^{2}$ such as repressing or forging, impregnation, heat-treating, machining, injection molding etc. These products exhibited superior mechanical properties compare to conventional $\mathrm{P} / \mathrm{M}$ products. It has been reported ${ }^{3,4}$ that mechanical properties of the final product were the function of the mode through which the maximum densification had been attained leaving aside the other influential factors such as material character-

*e-mail: rajeshkannan_a@yahoo.com

Department of Mechanical Engineering, Motilal Nehru National Institute of Technology, Allahabad - 211 004, Uttar Pradesh, India. istics and process parameters. Although, there are many modes for inducing high density in sintered $\mathrm{P} / \mathrm{M}$ parts, the cold deformation is considered to be a simple and flexible method of producing finished high density parts.

With the application of axial compressive stress the pores will collapse and ultimately closes, in the meanwhile density also enhances, whereas with the application of axial tensile stress, the pores will grow and densification will decrease. Even pure hydrostatic stress, can be accomplished through repressive mode of deformation, will cause a metal powder preform to yield as the yield surface is close on the stress axis, which is not true in fully dense material ${ }^{5}$. In any upsetting operation, the induced height strain would result in creating subsequent diametrical flow of the P/M preform material. However, a spherical pore would undergo flattening and simultaneous elongation in the direction of diametrical flow. The shear stress present along with the normal pressure ensures that there is relative motion between the opposite sides of the collapsing pores. Thus, the mechanical rupturing of oxide film is feasible, with virgin material being exposed for bond formation across the collapsing pore surfaces as described elsewhere ${ }^{6,7}$. Apart from the regular enhancement of densification and stress due to induced strain during cold forging, usually porous material would also experience strain-hardening characteristics ${ }^{8}$. This in fact reveals the means for the increase of flow stress $(\sigma)$ as the amount of axial strain $(\varepsilon)$ is increased. However, the rate of increase in the stress value with respect to strain is greater than that would be observed in a pore free material of the same composition under identical testing conditions, since the continued reduction in the porosity level during upsetting increases the load bear- 
ing cross - sectional area, which in turn increases the applied stress for further deformation. This results in strain hardening behaviour, and it is due to the combined effects of continued deformation and densification in a porous material. In addition finer particle size is beneficial for inducing strain hardening characteristic in $\mathrm{P} / \mathrm{M}$ preform as describe elsewhere ${ }^{9}$. It is reported ${ }^{10}$ that the strain hardening exponent (n) is always constant for wrought iron, whereas for sintered iron billets it is a function of the initial preform density. Therefore, strain hardening effect due to compressive deformation of porous billets must be taken into account when attempting to estimate the load requirements, design of preforms and dies used under cold upsetting operations.

The frictional forces developed between the workpiece and the forming tools are very essential to be considered for any of the metal working processes ${ }^{11,12}$. During the cold axial upsetting, heterogeneity in deformation is observed due to the existence of frictional constraints in between the workpiece and top \& bottom dies. Just beneath the faces of the flat dies, which are in contact within the workpiece, a conical wedge shaped relatively undeformed material is formed as shown in Figure 1.

But, the remaining materials tend to flow easily towards the nearest free surfaces where the resistance to metal flow is minimum ${ }^{13}$. Therefore, in cold upsetting, barreling become predominant in absence of the lubrication. However, the detrimental effects of friction can be minimized by the application of proper lubricants. Also, the benefits that can be derived by using lubricants are the reduction in barreling, improvement in surface finish and decrease in wear and tear of the tooling ${ }^{14}$. Densification process therefore, can be perceived as a combination of pore filling and vacancy destruction processes. However, the densification of the preforms by plastic deformation induces strain-hardening effect, which is strongly influenced by the stress state created in the material by the application of external loads. Thus, present investigation is aimed to investigate and to establish the technical relationship that existing between the applied stresses against induced height strain and the attained theoretical density during cold upsetting of sintered $\mathrm{Fe}-0.8 \% \mathrm{C}$ preforms under the influence of three different lubricating constraints.

\section{Experimental Details}

\subsection{Materials and characterization}

Atomized iron powder of $-150 \mu \mathrm{m}$ size was procured from $\mathrm{M} / \mathrm{s}$. The Sundaram Fasteners Limited, Hyderabad, India and graphite powder of $2-3 \mu \mathrm{m}$ was supplied by M/s. The Ashbury Graphite

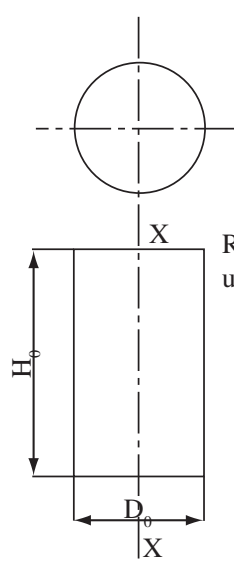

(a) Initial cylinder
XX Axis of symmetry

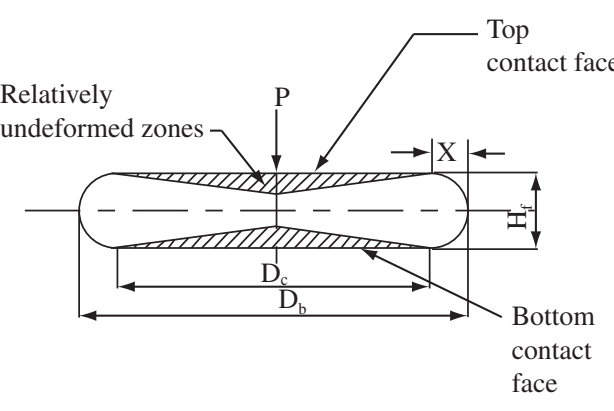

(b) Instantaneous barrel
Figure 1. Schematic representation of upset forging test specimen before and after deformation.
Mills Inc., Ashbury Warren County, New Jersey, USA. Analysis indicated that the purity of iron powder was $99.7 \%$ and the rest of it contains insoluble impurities. The characteristic of iron powder and iron $-0.8 \%$ carbon blend are shown in Table 1 and 2 .

\subsection{Blending, compaction and sintering}

The required amount of powders corresponding to $\mathrm{Fe}-0.8 \% \mathrm{C}$ were measured and blended in a pot mill along with porcelain balls of ratio $1: 1$ by weight for a period of 20 hours in order to obtain a homogeneous mix. This powder blend was further compacted on a $1.0 \mathrm{MN}$ capacity hydraulic press in the pressure range of $430 \pm 10 \mathrm{Mpa}$ to obtain the initial fractional theoretical density of $0.86 \pm 0.01$. These green compacts were sintered in an electric muffle furnace at temperature range of $1150 \pm 10{ }^{\circ} \mathrm{C}$ and maintained for 90 minutes. In order to avoid oxidation during sintering the compacts were ceramic coated. These sintered preforms were allowed to cool inside the furnace itself till they attained ambient condition.

\subsection{Cold deformation}

Sintered and furnace cooled preforms were machined to such a dimension so as to provide the preforms of constant initial aspect ratio of 0.40 . Initial dimension of the cylindrical preform were measured using digital vernier caliper and these measured geometries were used to calculate the initial density. Preforms of $\mathrm{Fe}-0.8 \% \mathrm{C}$ were axially deformed on a flat die set in the incremental loading step of $0.04 \mathrm{MN}$ each under different lubricating constraints such as nil/no, graphite and zinc stearate lubricants respectively. Dimensional measurements such as deformed height, deformed diameters (includes bulged and contact) were carried out simultaneously at every step of deformation, the density measurements were carried out using Archimedean principle $^{15}$. Data thus obtained have been used to calculate various parameters so as to establish the behaviour of applied stresses with respect to continuous deformation and densification. Further, an attempt has been made to establish the technical affirmation for the enhancement of strain hardening during continuous deformation and densification of the sintered eutectoid preforms.

\subsection{Parameters calculated}

From the experimental data, the following parameters were calculated:

a) True height strain $=\ln \left(\mathrm{H}_{0} / \mathrm{H}_{\mathrm{f}}\right)$

b) True diameter strain $=\ln \left(\mathrm{D}_{\mathrm{c}} / \mathrm{D}_{0}\right)$

c) Fractional theoretical density $=\rho_{\mathrm{f}} / \rho_{\text {th }}$

d) Engineering stress $=P / A_{0}$, where $A_{0}=\pi\left(D_{0}^{2}\right) / 4$

e) True stress $=P / A_{c}$; where $A_{c}=\pi\left(D_{c f}^{2}\right) / 4$

f) Poisson's ratio $=\left(\ln \left(\mathrm{D}_{0} / \mathrm{D}_{\mathrm{c}}\right)\right) /\left(\ln \left(\mathrm{H}_{\mathrm{f}} / \mathrm{H}_{0}\right)\right)$

Where, $\mathrm{H}_{0}$ is initial height of the preform; $\mathrm{H}_{\mathrm{f}}$ is forged height of the preform; $\rho_{\mathrm{f}}$ is forged density of the preform; $\rho_{\mathrm{th}}$ is the theoretical density of the selected composition; $\mathrm{D}_{\mathrm{c}}$ is forged contact diameter of the preform; $\mathrm{D}_{0}$ is initial diameter of the preform; $\mathrm{P}$ is applied load on the preform; $\mathrm{A}_{0}$ is the original area of cross section of the preform before it is forged. $A_{c}$ is the area of cross section at contact diameter of the preform after forged.

\section{Results and Discussion}

\subsection{Stresses and deformation}

Applied stresses includes both engineering and true stresses, which can be defined as the resistance to deformation offered by the material(preform) with respect to original area of cross section(before deformation) and instantaneous area of cross section during deformation respectively. The instantaneous dimensions of deforming preform 
Table 1. Characterization of Iron powder and eutectoid steel blend.

\begin{tabular}{clrr}
\hline Si. No. & \multicolumn{1}{c}{ Property } & \multicolumn{2}{c}{ Iron powder and Powder blend } \\
\cline { 3 - 4 } & & Iron & Fe-0.8\% \\
\hline 1. & Apparent Density $(\mathrm{g} / \mathrm{cc})$ & 2.96 & 2.87 \\
2. & Flow rate, $(\mathrm{s} / 100 \mathrm{~g})$ by Hall Flow Meter & 56.00 & 54.00 \\
3. & Compressibility $(\mathrm{g} / \mathrm{cc})$ at pressure of $430 \pm 10 \mathrm{MPa}$ & 6.55 & 6.50 \\
\hline
\end{tabular}

Table 2. Sieve size analysis of iron powder.

\begin{tabular}{cc}
\hline Sieve size $(\mu \mathrm{m})$ & wt. $(\%)$ ret. \\
\hline 150 & 10.14 \\
+126 & 21.90 \\
+106 & 9.46 \\
+90 & 2.02 \\
+75 & 20.10 \\
+63 & 12.10 \\
+53 & 11.10 \\
+45 & 5.70 \\
+37 & 0.31 \\
-37 & 7.00 \\
\hline
\end{tabular}

have been measured after the end of each step of incremental loading using digital vernier caliper. In order to establish the relationship on applied stresses as a function of continuous deformation a plot was constructed between engineering and true stresses against true height strain, which is shown in Figure 2.

The three different mechanisms can be described invariably for all the lubricating conditions that the first stage shows little rise in stress value, because the material starts offering resistance to deformation which means the initial application of load is just insufficient to deform the initial packing of sintered preform. However, in second stage, an extended deformation took place at uniform pace this influence the stress rise at steady state. In addition to the height strain, the diametrical spread out also takes place through out the deformation as the rise of true stress values are evident, however lateral expansion was substantial for the given induced strain in zinc stearate followed by graphite and dry friction respectively. Further, it is interesting to note that the divergences between engineering and true stresses are virtually distinct at the end of second stage (i.e., w.r.t. engineering stress curves 0.1 to 0.7 height strain value). This revealed the fact that up to second stage the height strain are substantial, thereafter the domination of diametrical strain occupies in the deforming preform. The third or final stage shows quite pronounced rate of engineering stress, which was not the fact for true stress, nevertheless it exhibits an index of strain hardening that made to resist the deformation little substantial.

\subsection{Stresses and densification}

In general, strength of any material can be broadly described as the ability of a material to withstand externally applied load up to its fracture. It is well established that the strength of P/M preform is governed by the maximum density that attained and the mode by which the density being attained. By virtue of the above phenomena, it can be claimed that the degree of material resistance against deformation is a function of attained density. Therefore, a plot has been constructed between applied stresses and percentage fractional theoretical density for $\mathrm{Fe}-0.8 \% \mathrm{C}$ - steel preforms and is shown in Figure 3. The influence of friction conditions is highlighted on a constant aspect ratio preforms during deformation. Although, the general behaviour of curves plotted in Figure 3 is as similar to that

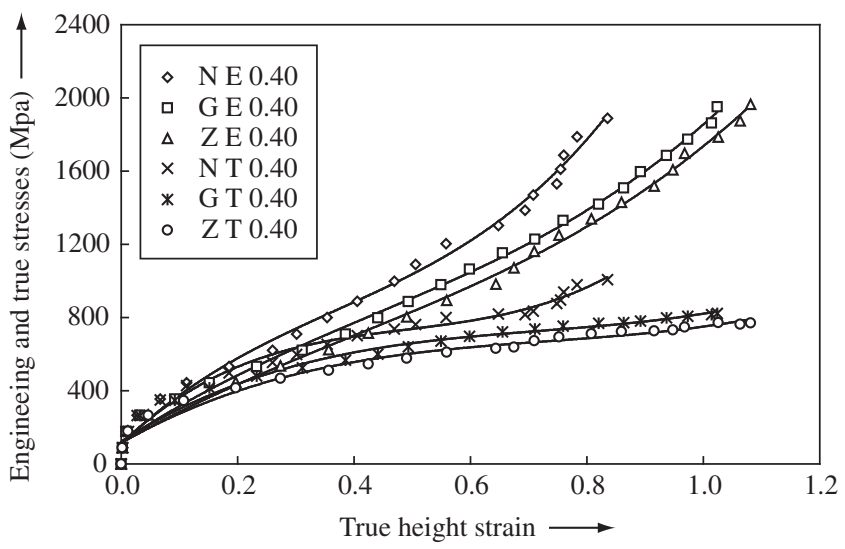

Figure 2. Relationship between applied stresses and the true height strain of sintered $\mathrm{Fe}-0.8 \% \mathrm{C}$ P/M preform of 0.40 initial aspect ratio under the influence of lubricants. N: Nil lubricant, G: Graphite Lubricant, Z: Zinc Stearate Lubricant, E: Engineering Stress, T: True Stress.

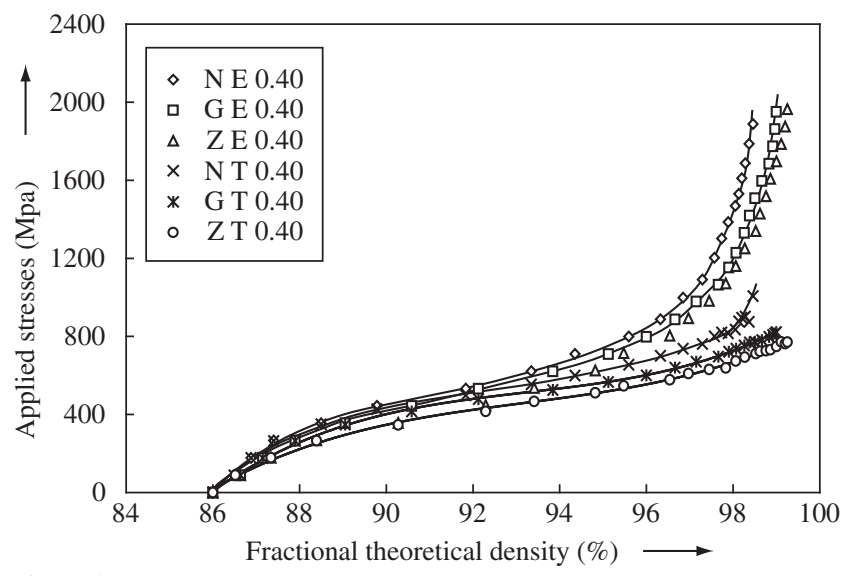

Figure 3. Relationship between applied stresses and the $\%$ fractional theoretical density for $\mathrm{Fe}-0.8 \% \mathrm{C}$ sintered $\mathrm{P} / \mathrm{M}$ preform of 0.40 initial aspect ratio under the influence of lubricants. N: Nil lubricant, G: Graphite Lubricant, Z: Zinc Stearate Lubricant, E: Engineering Stress, T: True Stress.

of Figure 2, the three different stages are more so following. At initial stages (from 86 to $88 \%$ theoretical density), the increase of stress rise is due to the resistance induced by the deforming porous preforms, which means the sintered material is little harden at initial stage that needs enhanced load to deform and thus to densify the preform. The second stage (from 88 to $97 \%$ theoretical density) conforms to a constant slope indicating the steady deformation of porous preform leading to collapsibility of pores, which induces the kinetics of densification that made to slow down the rise of stress values. However, at final stage the engineering stress values shown peak rise where as true stress values are falling down and the values are all accumulated in a closed region; this is because the preform attained maximum densification. Technically, these phenomena can be described that almost all the pores or pore beds present in the preform would have been collapsed (since preforms were attained 
on an average $98-99 \%$ density) by the different kinetics of particles such as translation, rotation and transformation with in the pores, due to the induced strain during deformation. The remaining pores would attain thermodynamically stable state and it is expected to behave as a second phase particle. Any application of extensive load will deform both material as well as pores at same pace laterally outwards. Thus, the extensive application of load in upsetting mode of deformation will yield the pores as crack formation at the free surfaces of deforming preform. The diametrical increase of preform during deformation to bear the load is the cause for the difference in engineering and true stress values and this effect is highly pronounced at the final stage of deformation. Another important point to be noticed is that the stress/ load at which the crack opening is originated should be identified in order to suggest the introduction of circumferential constraint (i.e., repressive mode of deformation) to reweld the crack opening and thus to produce metallurgically sound product. In regards with influence of lubricants, both graphite and zinc stearate extended the deformation before the maximum density attained by the preform. However, the value of applied stress was relatively low at any instant of density attained by the preform, which is the index of conformity that strength imparted or strain hardening induced is minimum when lubricants (i.e., graphite and zinc stearate) employed during deformation.

\subsection{Strain hardening characteristics}

An attempt has been made to determine the strain-hardening exponent graphically for $\mathrm{Fe}-0.8 \% \mathrm{C} \mathrm{P} / \mathrm{M}$ preforms in order to describe its effect during cold deformation under the influence of lubricants. Thus, the flow curve was plotted in $\log -\log$ scale to establish the linear relationship, by the process strain hardening (i.e., slope) can be easily determined. Figures $4 \mathrm{a}$ and $\mathrm{b}$ are the plots drawn between true stress in log scale to the true height strain and true diameter strain in $\log$ scale respectively for three different lubricating constraints.

The curve corresponding to nil lubricant constraint exhibits two different mechanisms shown in dashed line and continuous line and represented as segment 1 and segment 2 respectively. Whereas for graphite and zinc stearate lubricants, the respective curve technically follows single mechanism, which is shown by dashed line itself. The slope of the straight line in figures are equal to strain hardening exponents (n) in the expression $\sigma=k \varepsilon^{n}$, where $\sigma$ is true stress, $k$ is strength coefficient and $\varepsilon$ is true strain. However, the slope of each curve has been determined by measuring the angle ' $\theta$ ' through graphically with horizontal axis, which are presented in Table 3.

The critical observations of Figure $4 \mathrm{a}$ and $4 \mathrm{~b}$ reveals that strain hardening can highly be imparted for the preform deformed under nil lubricating condition through continuous deformation up to its maximum densification (i.e., prior to crack formation in the preform). Nevertheless, graphite and zinc stearate lubricants only extend the deformation without substantial improvement in strain hardening. These figures will not reveal strain hardening exponent for each step of strain induced during deformation, however this supports the theory described for Figures 2 and 3. Further, it can be observed from Table 3 is that the slope value obtained for true height strain and true diameter strain at the first segment are almost in par with one another which exhibits the fact that work hardening takes place both in linear and in lateral direction as well. Conversely, it can be proved that densification takes place in both axial as well as in transverse direction due to the induced strain. This conforms to the findings of earlier investigation ${ }^{16}$.

The relationship established for applied stress with continuous deformation and densification revealed that the stress rise being enhanced with the enhancement of the strain and density attained by the preform. This is due to the increase of work hardening during deformation. In order to ascertain the established relationship, further

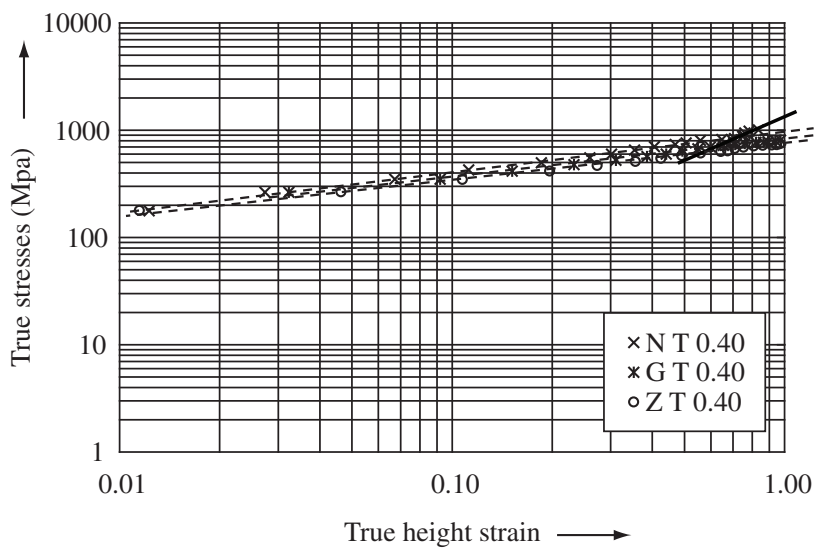

(a)

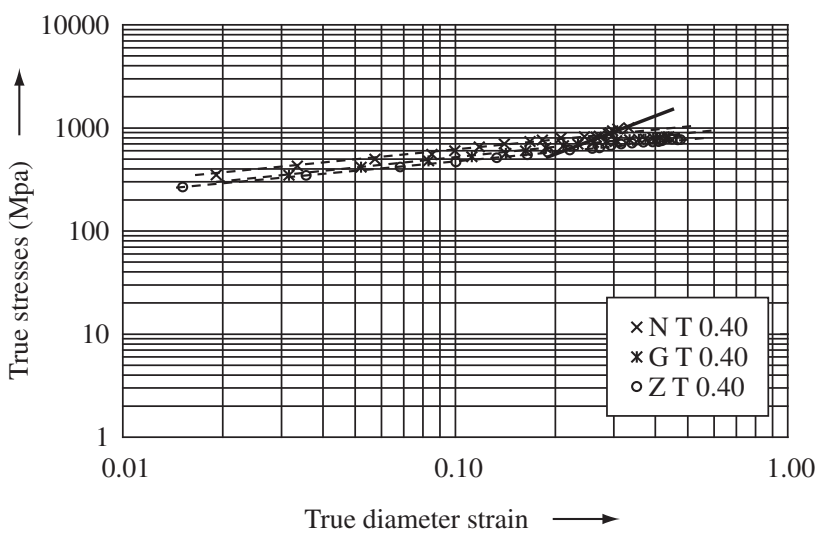

(b)

Figure 4. a) Flow curve between true stresses and true height strain in log, log scale; and b) Flow curve between true stresses and true diameter strain in log, log scale. Dashed line: Segment 1; Continuous line: Segment 2.

Table 3. Strain hardening co-efficient of flow curves.

\begin{tabular}{|c|c|c|c|}
\hline \multirow{2}{*}{$\begin{array}{l}\text { Lubricants } \\
\text { Employed }\end{array}$} & \multirow[t]{2}{*}{ Segments } & \multicolumn{2}{|c|}{ Slope $(\theta)$ in Degrees } \\
\hline & & $\theta_{\mathrm{h}}$ & $\theta_{\mathrm{d}}$ \\
\hline \multirow[t]{2}{*}{ Nil } & 1 & 6.6 & 5.8 \\
\hline & 2 & 22.6 & 20.9 \\
\hline \multirow[t]{2}{*}{ Graphite } & 1 & 6.5 & 6.1 \\
\hline & 2 & - & - \\
\hline \multirow[t]{2}{*}{ Zinc Stearate } & 1 & 6 & 5 \\
\hline & 2 & - & - \\
\hline
\end{tabular}

$\theta_{\mathrm{h}}$ and $\theta_{\mathrm{d}}$ are the slopes or angle of flow curves determined with true height strain and true diameter strain respectively.

plot have been constructed between instantaneous strain hardening exponent $\left(\mathrm{n}_{\mathrm{i}}\right)$ against percentage fractional theoretical density, true height strain and true stress respectively shown in Figures 5, 6 and 7. The theoretical descriptions for the determination of ' $n_{i}$ ' has been developed from the plastic flow equation $\left(\sigma=k \varepsilon^{n}\right)$ of fully dense material with little modification in order to suit for $\mathrm{P} / \mathrm{M}$ materials, which are as follows.

Assuming consecutive applied load on the preform were specified as 1, 2, 3,.., (m-1) and $m$. Now the plastic flow equation can be written as follows: 


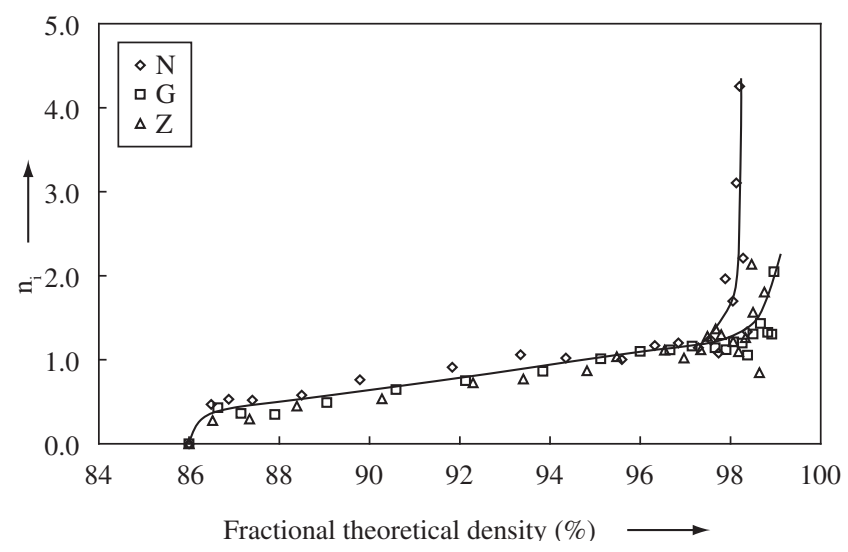

Figure 5. Relationship between instantaneous strain hardening exponent $\left(\mathrm{n}_{\mathrm{i}}\right)$ and $\%$ fractional theoretical density.

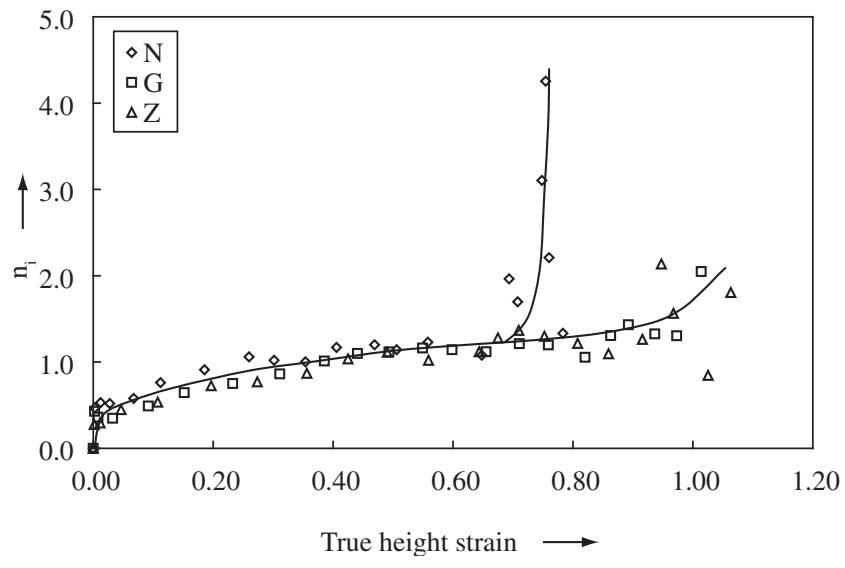

Figure 6. Relationship between instantaneous strain hardening exponent $\left(\mathrm{n}_{\mathrm{i}}\right)$ and true height strain.

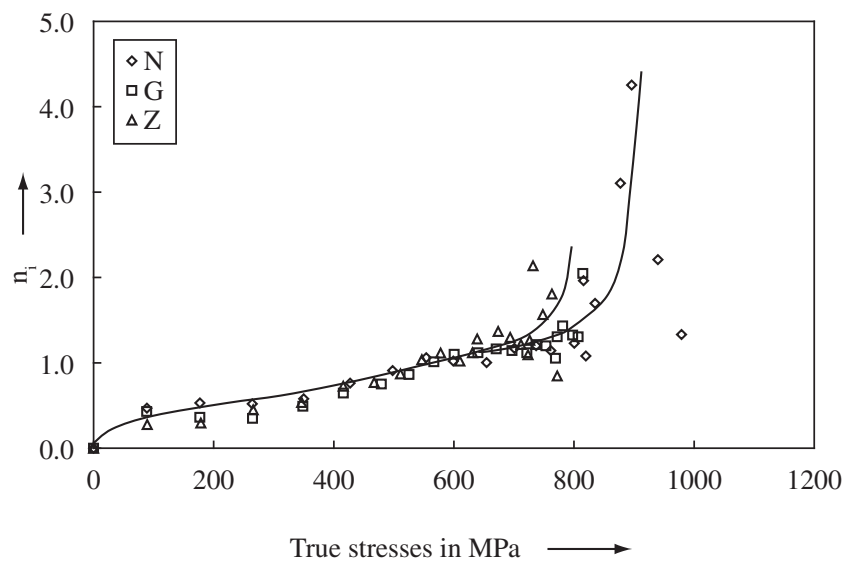

Figure 7. Relationship between instantaneous strain hardening exponent $\left(\mathrm{n}_{\mathrm{i}}\right)$ and true stresses.

$$
\begin{aligned}
& \sigma_{\mathrm{m}}=\mathrm{K} \varepsilon_{\mathrm{m}}^{\mathrm{n}} \\
& \sigma_{\mathrm{m}-1}=\mathrm{K} \varepsilon_{\mathrm{m}-1}^{\mathrm{n}}
\end{aligned}
$$

Dividing the Equation 1 by Equation 2, the following expression is obtained

$$
\frac{\sigma_{\mathrm{m}}}{\sigma_{\mathrm{m}-1}}=\frac{\varepsilon_{\mathrm{m}}^{\mathrm{n}}}{\varepsilon_{\mathrm{m}-1}^{\mathrm{n}}}=\left(\frac{\varepsilon_{\mathrm{m}}}{\varepsilon_{\mathrm{m}-1}}\right)^{\mathrm{n}}
$$

Taking natural logarithm on both sides of Equation (3), it follows,

$$
\ln \left(\frac{\sigma_{\mathrm{m}}}{\sigma_{\mathrm{m}-1}}\right)=\mathrm{n} \ln \left(\frac{\varepsilon_{\mathrm{m}}}{\varepsilon_{\mathrm{m}-1}}\right)
$$

Equation 4 can further simplify into

$$
\mathrm{n}_{\mathrm{i}}=\frac{\ln \left(\frac{\sigma_{\mathrm{m}}}{\sigma_{\mathrm{m}-1}}\right)}{\ln \left(\frac{\varepsilon_{\mathrm{m}}}{\varepsilon_{\mathrm{m}-1}}\right)}
$$

Equation 5 can be utilized for determining the instantaneous strain hardening exponent from the experimental data corresponding to stress and strain.

Figures 5, 6 and 7 uniquely express that the degree of increase of strain hardening is of three stages. Initially, strain hardening exponent increases slightly followed by an extended steady state and finally it attains the peak (the similar characteristic observation was found in Figures 2 and 3). However, the last stage was highly pronounced in case of nil lubricant condition. The same was not true for graphite and zinc stearate lubricating conditions except at initial two stages. Observation of Figures 5 and 6, uniquely expresses that preform deformed under dry friction is subjected to strain harden much faster as well as maximum, whereas preforms deformed under lubricating condition extended the deformation substantially and then it gets strain harden. In addition, the careful observation of these figures reveal that the values of strain hardening exponent for each induced strain and attained densification are observed to be higher for without employed lubricant condition in comparison to lubricant employed condition, which further ensures the truth that the rate of strain hardening was high in dry friction condition. However, Figure 7 exhibits, as an index of proof for the description stated for Figures 2 and 3 that the rise of stress values due to the hindrance of dislocation of particles will contribute directly to raise the strain hardening effect. Thus, it can be established that sintered preforms can be effectively cold deformed with ample strength induced due to work hardening effect.

\section{Conclusions}

It has been experimentally established and theoretically justified for the variation of engineering stress and the true stress w.r.t. the true height strain or the percentage fractional theoretical density exhibiting three different stages. The first stage exhibit the initial resistance of the preforms against deformation followed by the collapse of the pores and enhancement in densification, whereas the third stage corresponded to the extensive work hardening and ultimately resulting under the extreme cases as the appearance of cracks on the free surfaces of the deforming preforms. Thus, the ultimate stage restricts the limiting conditions of deformation and demanding for the introduction of repressing action to seal the surface appearing cracks.

Strain hardening exponents have been determined by measuring the slope of stress - strain curve plotted in $\log -\log$ scale. In addition to that, the instantaneous strain-hardening exponent was determined and is plotted for attained densification, induced strain and applied true stress respectively. This proved a maximum strain hardening and enhanced strain-hardening rate can be achieved for dry friction conditions during continuous deformation and densification of the 
preforms. Whereas, the application of lubricants has facilitated an extended deformation with the marginal increase of strain hardening up to its maximum theoretical densification attained or the surface cracks appears at the deforming preforms. Thus, sintered preforms can be successfully cold deformed with substantial strength induced due to the work hardening effect.

\section{References}

1. Ryuichiro Goto. Powder metallurgy growth in the automotive market. Business Briefing: Global automotive manufacturing and technology. 2003: 44-45.

2. Miska Kurt H. In: Samuel Bradbury, editor. Powder metal parts. Ohio: ASM Metals park; 1979: 1-9.

3. Pandey KS. Salient characteristics of high temperature forging of ferrous powder preforms. Key Engineering Materials. 1989; 465: 29-31.

4. German RM. Powder Metallurgy of Iron and Steel. New York: John Wiley \& Sons Inc; 1998. p. 276-308.

5. Lawley A. In.: Gilbert Y. Chin, editor. Advances in powder technology. New York: ASM Materials Science Seminar, ASM; 1982.

6. Kuhn HA, Downey CL. How flow and fracture affect design of preforms for powder forging. International Journal of Powder Metallurgy and Powder Technology. 1974; 10(1): 59-66.

7. Kuhn HA. Powder metallurgy processing. New York: Academic press; 1978. p. 99-138.
8. Hansen. N. Dispersion strengthened aluminium products manufactured by powder blending. Powder Metallurgy. 1969; 12(23): 23-44.

9. Narayanasamy R, Pandey KS. Some aspects of work hardening in sintered aluminium - iron composite preforms during cold axial forming, Journal of Material Processing Technology. 1998; 84: 136-142.

10. El Wakil SD. Plasticity theory of sintered iron powder compacts. Proceedings of The 15th International Conference on Machine Tool Design and Research; Birmingham, UK, London: Macmillan; Sep 1974. p. 645.

11. Ball WG, Higher FW, Mckotch RA, Pfingstler HD. In: Edward N. Aqua, Charles I. Whitman. editors. Advances in Powder Metallurgy and Particulate Materials. 1994. 3: 71-80.

12. Ball WG. New die - wall lubrication system. International Journal of Powder Metallurgy 1997; 33(1): 23-30.

13. Narayanasamy R, Pandey KSA study on the barreling of sintered iron preforms during hot upset forging. Journal of Material Processing Technology. 2000; 100: 87-94.

14. Huppmann WJ, Brown GT. The steel powder forging process - a general review. Powder Metallurgy 1978; (2): 105-112.

15. Moyer KH. Measuring density of P/M materials with improved precision. International Journal of Powder Metallurgy and Powder Technology. 1979; 15: 33-42.

16. Pandey KS. Some investigations on the cold deformation behaviour of sintered aluminium-4\%copper alloy powder preforms. Journal of Powder Metallurgy Science and Technology. 1991; 2(4): 35-44. 